\title{
Deciphering Physiological Basis of Yield Gain in Indian Wheat Cultivars
}

\author{
S. GUPTA ${ }^{1}$, R. YADAV ${ }^{1 *}$, K.B. GAIKWAD ${ }^{1}$, A. ARORA ${ }^{3}$, A. Kumar ${ }^{1}$, \\ A. KuSHWAH ${ }^{2}$ and N.K. BAINSLA ${ }^{1}$ \\ ${ }^{1}$ Division of Genetics, Indian Agricultural Research Institute, New Delhi 110012, India \\ ${ }^{2}$ Department of Plant Breeding and Genetics, Punjab Agricultural University, Ludhiana 141004, Punjab, India \\ ${ }^{3}$ Division of Plant Physiology, Indian Agricultural Research Institute, New Delhi 110012, India
}

(Received 26 July 2016; Accepted 6 December 2016; Communicated by T. Harangozó)

\begin{abstract}
Physiological breeding complementing the conventional approach is increasingly being explored in wheat in view of stagnating annual genetic yield gain. Designing improved plant types required knowledge about physiological traits associated with yield gain in the past. Fourteen wheat varieties including 12 historically important and popular (mega) wheat cultivars and two recently registered varieties were observed for various physiological traits for two years. Both breeding period and genotypes within breeding period accounted for significant differences for most of the physiological traits. Regression analysis indicated curvilinear trend for leaf area index (LAI), flag leaf area, and root length and root weight. Near perfect leaf area index (LAI 5.94) with semi-erect leaves and higher flag leaf area was observed in all time mega variety HD 2967 indicated the importance of plant architecture and crop canopy in yield maximization. Linear declining trend was observed for coleoptile length, number of stomata per $\mathrm{cm}^{2}$ and flag leaf length. Increasing trend for total chlorophyll content and normalized difference for vegetative indices (NDVI) at both vegetative and flowering stage indicated the importance of leaf greenness in yield improvement. Root length has continuously declined except for the latest released varieties, however no such trend was observed for root weight. We propose that grain yield stabilization at still higher level can be achieved by increasing photosynthetic capacity, optimizing the crop canopy slightly less than the optimum, and better partitioning to grain yield through directed physiological based breeding.
\end{abstract}

Keywords: wheat, genetic gain, physiological traits, breeding period, regression analysis

\section{Introduction}

Wheat (Triticum aestivum L.) is a crop of global significance and it provides more nourishment for humans than any other cereal crop. Annual genetic gain in wheat yield needs to be accelerated beyond 1 per cent to outpace the growing global demand. Deteriorating production environment and changing climatic conditions are also challenging such realization. During the last century, genetic gain in wheat yield ranged annu-

*Corresponding author; E-mail: rajbiryadav@yahoo.com 
ally from $0.3 \%$ to $1.0 \%$ (Graybosch and Peterson 2010). Genetic gain has largely been attributed to reduced plant height with better allocation of assimilate toward sink resulting in significantly improved harvest index (Foulkes et al. 2011). Further improvement in HI (Alvaro et al. 2008) is very hard to come as modern cultivars are very close to theoretical limits of 0.62 (Austin et al. 1980). Increased biomass with inbuilt lodging tolerance advocated as a mean of achieving a breakthrough (Sadras and Lawson 2011; Sanchez-Garcia et al. 2013) needs identification of physiological efficient genotypes through multidisciplinary team effort with better tools and techniques. Improved gas exchange, chlorophyll oriented better photosynthetic rate (Reynolds et al. 2000; Tian et al. 2011) and post-anthesis stomatal conductance for canopy cooling are advocated as a mean of further increasing the yield up to $50 \%$ in wheat (Fischer 2007; Flood et al. 2011; Reynolds et al. 2011). Breeders throughout the world including India have achieved significant gain in productivity without employing physiological selection tools (Rajaram and van Ginkel 1996).

Comparison of historic collections of mega varieties provides clue for quantification of yield improvement attributable to physiological traits and insight into the associated changes in phenotype. Knowledge of associated changes in physiological traits, which are very near to basic plant processes, along with yield improvement achieved over the years is also essential to identify the yield limiting factors for future gain. Despite its importance, studies on physiological basis of yield gain of wheat cultivars have been paid little attention in India. In this paper, we have discussed the results obtained on historical mega varieties of North Western Plain Zone (NWPZ) since the beginning of $20^{\text {th }}$ century till date to address areas of importance in relation to the physiological basis of breeding superior wheat cultivars which could potentially be applied to cultivar improvement.

\section{Materials and Methods}

\section{Plant material}

Field experiment was conducted with 14 wheat genotypes including 12 mega varieties( NP4, C 591, Sonora 64, Kalyan Sona, HD 2009, WL 711, HD 2329, WH 542, PBW 343, DBW 17, PBW 550, HD 2967) of North Western Plain Zone (NWPZ) of India along with one recently released (HD 3086) and one newly registered genotype (HDCSW 16). The plant material was arranged in Randomized Block Design (RBD) with two replications during 2012-2013 and 2013-2014 cropping seasons at the experimental farm of Indian Agricultural Research Institute, New Delhi. Varieties studied are presented along with their year of release in Table S1*. Sowing was done in the first fortnight of November, in six rows spaced at $20 \mathrm{~cm}$ in a plot of 5 meters length. Recommended package and practices including plant nutrition, irrigation, weed management and crop protection were followed to create non yield limiting environment. Non-shading net was used over each plot to avoid lodging. Weather data of the reported years are presented in Table S2.

*Further details about the Electronic Supplementary Material (ESM) can be found at the end of the article. 


\section{Observations recorded}

Chlorophyll content was estimated by adding $0.05 \mathrm{~g}$ fresh leaf samples (small discs) to the test tubes containing $10 \mathrm{ml}$ DMSO (Hiscox and Israelstam 1979). Tubes were kept in dark for $4 \mathrm{~h}$ at $65^{\circ} \mathrm{C}$. The absorbance was recorded at $663 \mathrm{~nm}$ and $645 \mathrm{~nm}$ using DMSO as blank and was expressed as $\mathrm{mg} \mathrm{g}^{-1}$ fresh wt. Chlorophyll content was estimated using the formula given by Arnon (1949). Ten properly germinated seeds of each variety were placed over hydroponics solution to study the root traits. After 15 days, root length was measured and roots were dried at 60 degree centigrade using hot air oven for 24 hours and weight of dried roots were recorded. Ten seeds were germinated on moist paper towel in germination chamber at $20^{\circ} \mathrm{C}$ temperature.

Coleoptile length was measured using graduated scale in centimeter. Data for Normalized Difference for Vegetative Index was recorded for each plot using optical handheld Green Seeker sensor (Trimble Industries, Inc.) at 90 days (NDVI 1) and 120 days (NDVI 2) after seeding. Leaf area was measured by leaf area meter and divided by ground area to obtain leaf area index. Flag leaf length and width was measured by scale whereas flag leaf area was measured by leaf area meter. Number of stomata present in one cm square on flag leaf was counted under compound microscope for all the genotypes studied.

\section{Statistical analysis}

Mixed model analysis of variance (ANOVA) was performed for all the traits under study. In the model used for ANOVA, the genotype effect was partitioned into breeding period considered as a fixed effect and genotype within breeding period considered as a random effect. Regression analysis was used for modelling the relation between year of release and the traits under study. Regression models, linear or polynomial (cubical) when appropriate, were fitted to the relationships. The coefficient of determination $\mathrm{R}^{2}$ indicating the proportion of the variance in the dependent variable that is predictable from the independent variable was calculated for each trait using Microsoft Excel program.

\section{Results}

\section{Leaf area index (LAI) and flag leaf area}

Leaf area index is considered as an important parameter for light interception. Analysis of variance revealed significant differences among breeding period and genotypes within breeding period (Table 1). Regression analysis showed a poor increasing linear trend over the years. Curvilinear regression analysis did not improve the fitness of the data. Highest LAI (5.945) was observed in one of the recent mega variety HD 2967 whereas lowest value (2.056) was observed in the first dwarf introduction named Sonora 64. Linear regression analysis revealed linear and increasing trend for leaf area index (Fig. 1). Flag leaf being the nearest source of assimilate production and supply along with developing ear, they play the most important role during grain filling in $\mathrm{C}_{3}$ cereals including wheat. Analysis of variance shows that in every phase of varietal development, there were geno- 


\begin{tabular}{|c|c|c|c|c|c|c|}
\hline 焉 च & $\stackrel{1}{\stackrel{n}{a}} \pm$ & & * & * & * & $\stackrel{\text { กิ }}{-}$ \\
\hline 커으 & $\stackrel{\frac{1}{c}}{\stackrel{N}{a}}$ & & * & * & * & $\stackrel{\infty}{\stackrel{0}{0}}$ \\
\hline 己ే & $\frac{b}{\vec{s}} \pm$ & & $*$ & $*$ & * & ă \\
\hline$\checkmark$ & $\stackrel{b}{\stackrel{n}{a}} \pm$ & & $*$ & $*$ & * & $\stackrel{+}{\grave{0}}$ \\
\hline 之 & $\stackrel{1}{\stackrel{1}{*}}=$ & & * & * & $*$ & $\vec{\sigma}$ \\
\hline 二 & 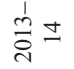 & & $*$ & * & $\tilde{Z}$ & $\stackrel{\hat{\imath}}{0}$ \\
\hline 之 & $\stackrel{1}{\stackrel{1}{ }}=$ & & * & * & $*$ & $\stackrel{0}{?}$ \\
\hline 若营 & $\stackrel{\frac{1}{2}}{\stackrel{\sim}{a}} \pm$ & $\tilde{Z}$ & $*$ & * & $*$ & 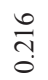 \\
\hline 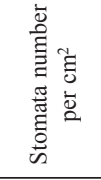 & $\begin{array}{l} \pm \\
\vec{n} \\
\stackrel{\sim}{\sim}\end{array}$ & $\tilde{Z}$ & * & $*$ & $*$ & ते \\
\hline $\begin{array}{l}\frac{\vec{E}}{\vec{b}} \\
\frac{\vec{g}}{\sigma}\end{array}$ & $\frac{1}{\stackrel{d}{c}} \pm$ & $\tilde{Z}$ & $*$ & $*$ & $*$ & $\begin{array}{l}\tilde{D} \\
i \\
i\end{array}$ \\
\hline$\frac{0}{0}$ & $\stackrel{1}{2}=$ & $\tilde{Z}$ & $*$ & $*$ & $*$ & $\stackrel{a}{i}$ \\
\hline 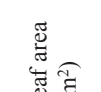 & $\frac{1}{\stackrel{n}{c}} \pm$ & Z & $*$ & $*$ & $*$ & $\vec{a}$ \\
\hline 焉 & $\stackrel{1}{\underset{2}{2}}=$ & $\tilde{Z}$ & $*$ & $*$ & * & $\vec{\sigma}$ \\
\hline 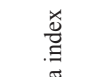 & $\frac{1}{\vec{c}} \pm$ & $\tilde{z}$ & $*$ & * & $*$ & $\stackrel{m}{\vec{r}}$ \\
\hline 芯 & $\stackrel{1}{\stackrel{1}{2}}=$ & $\tilde{Z}$ & $*$ & $*$ & * & $\stackrel{n}{n}$ \\
\hline \multicolumn{2}{|c|}{ 岁 } & - & $\cong$ & in & $\infty$ & \\
\hline \multicolumn{2}{|c|}{ 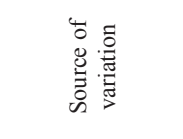 } & 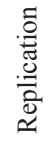 & 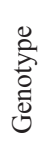 & 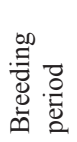 & 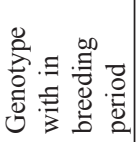 & $\stackrel{\Xi}{\Xi ँ}^{\tilde{E}}$ \\
\hline
\end{tabular}

Cereal Research Communications 45, 2017 


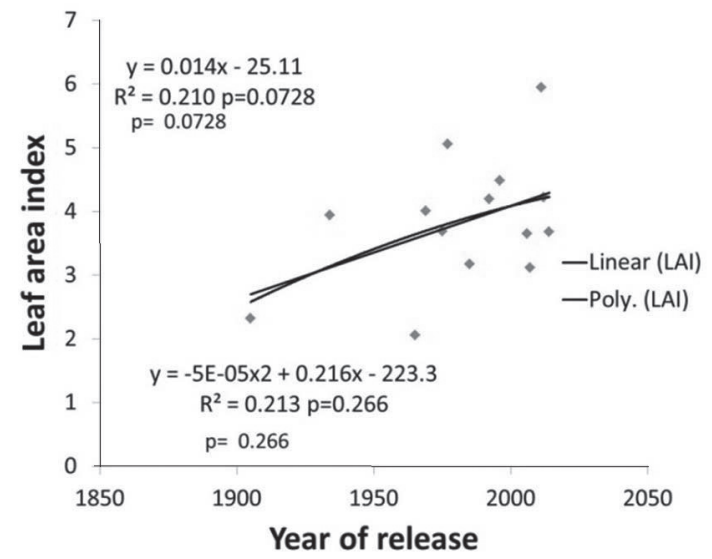

Figure 1. Regression analysis for leaf area index

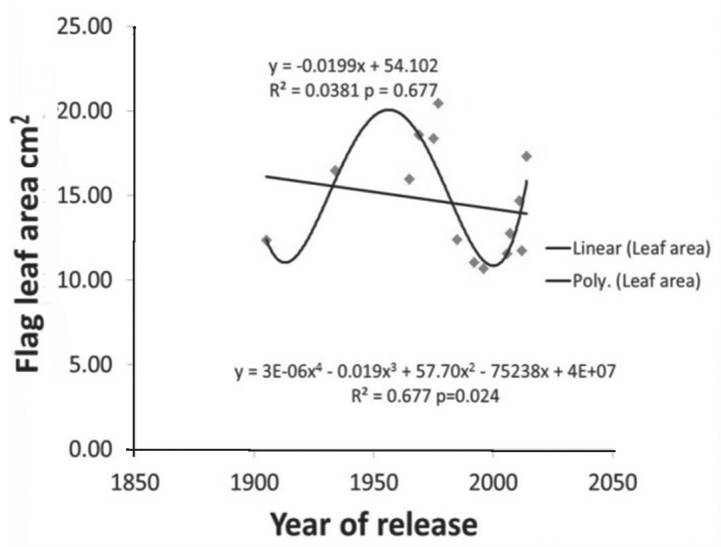

Figure 2. Regression analysis for flag leaf area

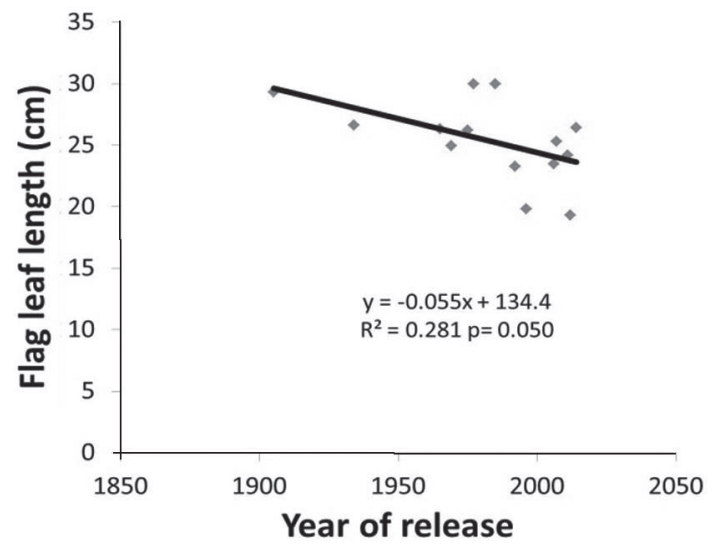

Figure 3. Regression analysis for flag leaf length 


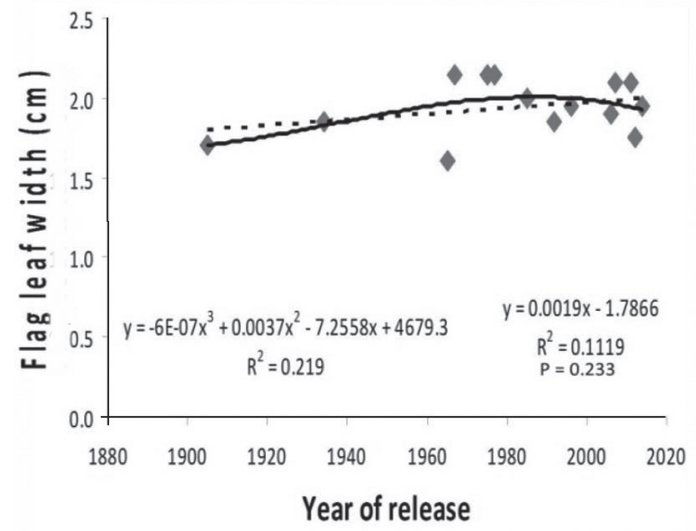

Figure 4. Regression analysis for flag leaf width

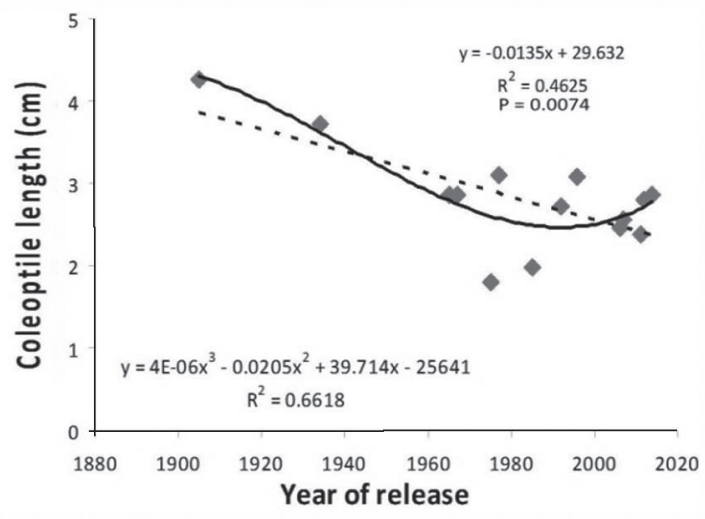

Figure 5. Regression analysis for coleoptiles

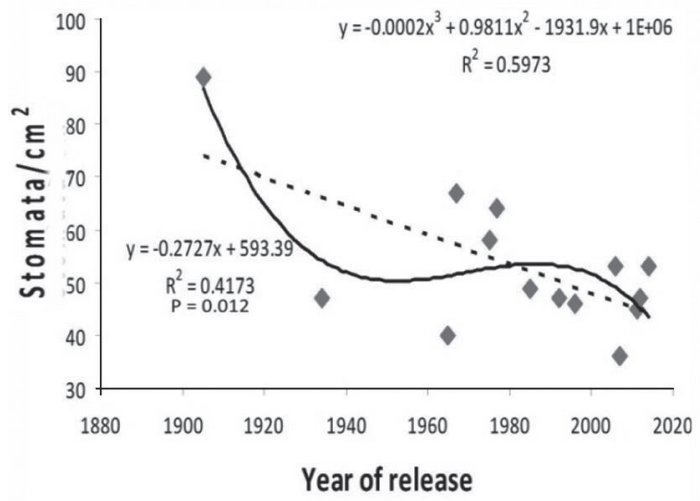

Figure 6. Regression analysis for stomata/ $\mathrm{cm}^{2}$ length 
types which differed from each other for the trait. Linear regression analysis revealed no trend for flag leaf area (Fig. 2), however higher order curvilinear analysis clearly $(p=0.024)$ established that flag leaf area increased till the introduction of dwarf varieties, followed by sharp drop and subsequent gain in recent varieties. The two dominating varieties of 1B/1R phase, i.e. PBW 343 and WH 542 and subsequently derived varieties using the similar parentage, viz. DBW 17, PBW 550 and HDCSW 16 have distinctly lower flag leaf area. Maximum flag leaf area of $25.2 \mathrm{~cm}^{2}$ was observed in WL 711, the variety developed by crossing dwarfing genes introductions. There is indication of continuous decline in flag leaf length over the years (Fig. 3), however, simultaneous increase in flag leaf width (Fig. 4) more particularly during green revolution phase (1966-1985) increased flag leaf area significantly. The sharp fall in flag leaf area due to drop in flag leaf length and comparatively lesser increase in width happened in the era when $1 \mathrm{~B} / 1 \mathrm{R}$ varieties were dominating, i.e. after 1995 and up to 2010. However, the flag leaf area was again increased significantly with recently released non-1B/1R varieties, i.e. HD 2967 and HD 3086. The reduced flag leaf area in the era of IB/IR may have been compensated by the number of chloroplast per unit area and the angle of leaf.

\section{Coleoptile length}

Coleoptile plays an important role in stand establishment, however, introduction of dwarfing Rht genes, more particularly $R h t B 1$ and $R h t D 1$ have reduced the coleoptile length dramatically. ANOVA revealed significant differences among the genotypes between breeding periods as well as genotypes within breeding periods for coleoptile length (Table 1). Regression analysis showed a linear declining trend at the rate of $0.0135 \mathrm{~cm}$ per year (Fig. 5). Coleoptile length was around $4 \mathrm{~cm}$ in the taller wheat varieties and it was reduced to around $3.0 \mathrm{~cm}$ in the dwarf introduction Kalyan Sona. It was further reduced to around $2.0 \mathrm{~cm}$ in HD 2329, a variety which dominated north western plain zone for quite long time. During the era of IB/IR dominance (PBW 343), coleoptiles length was slightly improved, however, in modern day varieties without 1B/1R like HD 2967 and HD 3086, it was again reduced. Linear regression was better fit to the data. Reduced coleoptile length restricts the wheat seeding to the top layer of the soil and therefore making the crop more prone to lodging as well as uneven stand establishment. Exploitation of alternate dwarfing gene offers the opportunity to realize early ground cover, better stand establishment without increasing the plant height.

\section{Stomatal density $\left(\mathrm{cm}^{2}\right)$}

Stomata plays an important role in maintaining the canopy temperature, particularly in Indian subcontinent where the temperature rise is very sharp during grain development stage, resulting in heavy yield penalty. However, higher number of stomata increased penalty for energy requirement in plants. Analysis of variance was significant for breeding period of genotypes and genotypes within breeding period for the studied trait (Table 1). Numbers of stomata in Indian wheat varieties in the last century are declining 
at linear rate of 0.272 stomata per $\mathrm{cm}^{2}$ continuously. Both linear and polynomial regressions were able to explain the variation in the data. Polynomial analysis shows that after initial sharp decline it slightly increased with the introduction of dwarf wheat varieties and again dropped among the newer strains (Fig. 6). Maximum number of stomata was observed in initial tall variety namely NP 4 and the least in PBW 550.

\section{Chlorophyll content}

Photosynthesis basically converts $\mathrm{CO}_{2}$ into sugar and the conversion requires energy which is supplied by chlorophylls and carotenoids by absorbing light. However, there exist no straight relationship between chlorophyll content and photosynthetic efficiency but being one of the important factor for the process, the chlorophylls ' $a$ ' and ' $b$ ' were estimated in all the cultivars released since 1905 to assess the variability and trend. Despite significant differences in content, both simple and cubical regression analysis indicates a mediocre increasing trend for both type of chlorophyll (Figs 7 and S1). Linear regression analysis was able to capture 20 and 23 per cent variation in the data, for chlorophyll 'a' and 'b', respectively. No trend was observed for total chlorophylls content (Fig. S2). Maximum chlorophyll content was observed in variety PBW 550 and was followed by Kalyan Sona.

\section{Root length and root weight}

Plants respond to different concentration of nutrient by altering root morphology including length, nutrient uptake rate and root weight. As all of these parameters can be selected for and against for making impact on shoot biomass, it was imperative to analyze the trend over the years. In our study, despite significant differences for breeding period as well as genotypes within breeding period for root length and root weight (Table 1), no trend was established for these parameters (Figs S3 and S4). Longest roots were observed

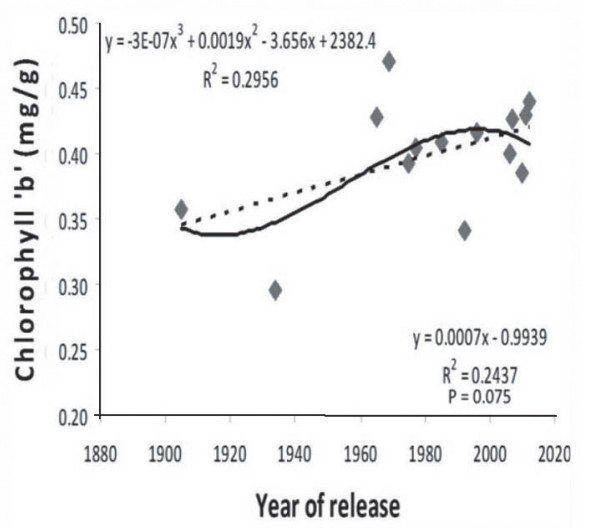

Figure 7. Regression analysis for chlorophyll 'b' 


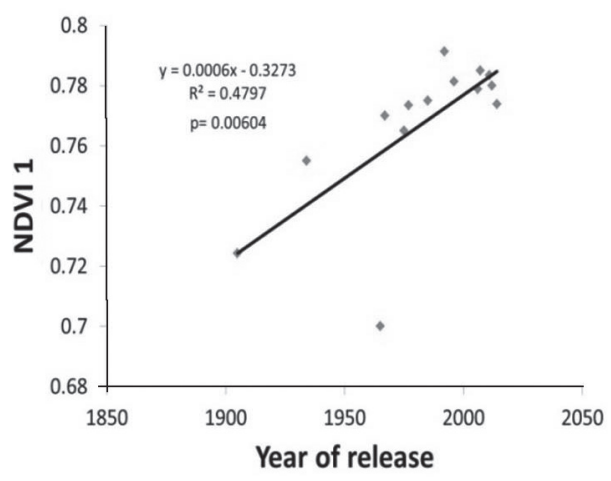

Figure 8. Regression analysis for NDVI 1

in genotype WL $711(25.3 \mathrm{~cm})$ and followed by one very old, C $591(23.2 \mathrm{~cm})$ and one very recent variety, HD $2967(23.1 \mathrm{~cm})$. In the present study, root length was studied in hydroponics for limited period and therefore gives only preliminary indication and requires further confirmation. Similarly, there exist huge variability for root weight (an indirect indication of root volume) and maximum root weight was observed in WH 542. Both recent varieties, namely HD 2967 and HD 3086, showed quite high root biomass. Not availability of any trend for these traits indicates their complex relationship with yield and therefore require more systematic and in depth study. However, within mega varieties of different period, enough variability for both of these parameters is available and therefore can be exploited but only after establishing their relationship with yield under different ecology and agronomy.

\section{Normalized Difference for Vegetative Index (NDVI)}

The normalized vegetative difference index is an estimator of LAI and is a better estimator of light interception by canopies. Linear regression for NDVI 1 around heading stages was able to explain 47.9 per cent variation in the data and shows clear cut increasing trend, however, at lateral stages no trend was observed for NDVI (Figs 8 and S5).

\section{Discussion}

To outpace the demand of wheat in the future through yield enhancement, multidisciplinary research effort in designing and selection of physiologically efficient plant is essential. Leaf area index, which measure light capturing ability of the genotype, around 6.0 is considered ideal for wheat canopies and many studies world over indicate the continuous improvement in leaf area index (López-Castaneda et al. 1996; Richards 2000; Tian et al. 2011). LAI of all time present day mega variety HD 2967 is very close to the ideal figure of 6.0. Rapid leaf growth is beneficial in non-limiting environment condition (Condon et al. 2004), however, with most of area under wheat in India being prone to terminal heat 
and water deficit stress, such genotype are more prone to terminal stress (Austin et al. 1980) and probably higher yield stabilization can be achieved with slightly lower LAI than the ideal figure of 6.0. Radiation use efficiency can be improved by designing the plant canopies in a way which promote light capturing (Parry et al. 2011) and preponderance of varieties with upright leaves in recent years indicates that majority of the breeders subscribe to this view. Sharp decline in productivity in some of the area with large scale acreage of HD 2967 in 2013-2014 and 2015-2016 due to strong heat stress at terminal stage substantiate the view. Beside LAI, another interesting observation is that flag leaf length has continuously declined with corresponding but comparatively lesser increase in width. In wheat and rice, canopy top captures maximum light (Zheng et al. 2011) and reducing the panicle/spike height below top leaves or by allowing more light to lower canopy through more erect and small flag leaf (Horton 2000) or initially erect flag leaf with higher leaf area and then bending from middle like in HD 2967 offers further way of improving crop photosynthesis. Area and orientation of flag leaf beside crop canopy is very important as 60 per cent of grain saccharides are derived from photosynthates in the flag leaf (Thorne 1974). Genetic manipulation of leaf orientation, size and thickness therefore can be further explored. Many retrospective analyses show that empirical selection for yield and its component traits in last century failed to increase photosynthesis per unit area (Richards 2000), however; physiological breeding approach still offers large scale opportunities. The analysis established an increasing trend for chlorophyll ' $a$ ' and NDVI 1 and therefore; indicate the better photosynthesis per unit area also in the modern cultivars. Chlorophyll content have never been under selection because of difficult in application over large segregating material and therefore indirect measurement of greenness through newer tools like green seeker offers opportunities for further yield consolidation. Present analysis also indicate clear decreasing trend in stomata number over the years. The reduced number of stomata over the period has resulted into better fitness of genotypes against the respiration and photorespiration more particularly under the condition of higher biomass with fluctuating water and temperature regime. Fischer et al. (1998) also found positive correlation of photosynthetic rate, canopy temperature depression and stomatal conductance with the gain in seed yield among varieties released in Mexico from 1932 to 1988 . Better root system is essential for nutrient and water uptake and thereby growth of the shoot. Complex interaction happens between root and soil surface, more particularly in top soil. Because of difficulty in measurement, these traits have remained largely unexplored and many researchers (Lynch 2007) feel that these are new frontiers for increasing productivity. Declining trend for root length in the mega cultivar of north western plain zone of India seems to be largely because of continuously increasing irrigation facilities and better nutrient application led to lesser and lesser investment by plants toward roots. Efficient root system, which captures more resources with lower investment in root system development, should be given more emphasis than root length and volume (Lynch 2007). Slightly longer root in some of the recently released varieties can improve their adaptability to resource scarce conditions, increase yield by improving water use efficiency (Kirkegaard et al. 2007; Richards et al. 2010). Increased photosynthesis and improved partitioning of assimilate toward spike without any structural adjustment may 
lead increased incidence of stem and root lodging (Foulkes et al. 2011). The conclusion drawn from the present analysis suggest that better crop canopy by increasing LAI as well as delayed senescence of flag leaf has increased the photosynthesis over entire life cycle of modern wheat. Biological yield can be theoretically improved through increased production of photosynthetic assimilate, declined respiration and improved translocation toward sink. Modern Indian cultivars clearly have better assimilate production not only by capturing more light but also due to higher chlorophyll content and lesser respiration as indicated by declined number of stomata. Increase in chlorophyll content in modern cultivars was also indicated by Sadras and Lawson (2011).

Significant differences in genotypes for majority of traits studied offer further scope for improvement of these traits, however, the gain has to be channelized through appropriate modulation of plant type, agronomy and physiological efficiency. This also suggests that breeding methodology has to be redesigned in order to further broaden the genetic base and population improvement like approaches including easily measureable physiological traits have to deploy for further gains.

It is clear from the analysis, that most of the traits supposed to be directly influencing the basic physiological mechanism defining yield like total chlorophyll content, flag leaf width, length and area failed to show any strong linear trend with year of release, however, their direction of change is in confirmation of previous studies and increasing photosynthetic capacity through their exploitation is more justified under likely $\mathrm{CO}_{2}$ enriched environment. Other traits like leaf area index, NDVI at ear emergence, coleoptile length, and number of stomata/ $\mathrm{cm}^{2}$ clearly establish the relationship with the year of release and therefore can be further explored for yield improvement. Highly optimized LAI in the recently released variety HD 2967 can be slightly compromised to induce yield stability under uncertain production environment at terminal crop growth stage of Indian subcontinent. We also suggest that crop photosynthesis can be increased by integrating physiological and agronomic perspective in crop breeding with equal emphasis on trade-offs (Sadras and Lawson 2011) between biomass partitioning and lodging. Fine tuning the morphological constrains for better plant resource allocation and optimizing the physiological processes by abandoning the notion of single optimal solution under all environments can be rewarding in the future.

\section{Acknowledgements}

The first author gratefully acknowledges the Indian Council of Agricultural Research (ICAR) for providing fellowship for the Master's Degree program.

\section{References}

Arnon, D.I. 1949. Copper enzymes in isolated chloroplasts, polyphenol oxidase in Beta vulgaris. Plant Physiol. 24:1-15.

Alvaro, F., Isidro, J., Villegas, D., del Moral, L.F.G., Royo, C. 2008. Old and modern durum wheat varieties from Italy and Spain differ in main spike components. Field Crops Research 106:86-93. 
Austin, R.B., Bingham, J., Blackwell, R.D., Evans, L.T., Ford, M.A., Morgan, C.L., Taylor, M. 1980 Genetic improvements in winter wheat yields since 1900 and associated physiological changes. J. Agricult. Sci. 94:675-689.

Condon, A.G., Richards, R.A., Rebetzke, G.J., Farquhar, G.D. 2004. Breeding for high water use efficiency. J. Exp. Bot. 55:2447-2460.

Fischer, R.A., Rees, D., Sayre, K.D., Lu, Z.M., Condon, A.G., Saavedra, A.L. 1998. Wheat yield progress associated with higher stomatal conductance and photosynthetic rate, and cooler canopies. Crop Sci. 38:1467-1475.

Fischer, R.A. 2007. Understanding the physiology basis of yield potential in wheat. J. Agricult. Sci. 145:99113.

Flood, P.J., Harbinson, J., Aart, M.G.M. 2011. Natural genetic variation in plant photosynthesis. Trends in Plant Sci. 16:327-335.

Foulkes, M.J., Slafer, G.A., Davies, W.J., Berry, P.M., Sylvester-Bradley, R., Martre, P., Calderini, D.F., Griffiths, S., Reynolds, M.P. 2011. Raising yield potential of wheat. III. Optimizing partitioning to grain while maintaining lodging resistance. J. Exp. Bot. 62:469-486.

Graybosch, R.A., Peterson, C.J. 2010. Genetic improvement in winter wheat yields in the great plains of North America, 1959-2008. Crop Sci. 50:1882-1890.

Hiscox, J.D., Israelstam, G.F. 1979. A method for the extraction of chlorophyll from leaf tissue without maceration. Can. J. Bot. 57:1332-1334.

Horton, P. 2000. Prospects for crop improvement through the genetic manipulation of photosynthesis: morphological and biochemical aspects of light capture. J. Exp. Bot. 51:475-485.

Kirkegaard, J.A., Lilley, J.M., Howe, G.N., Graham, J.M. 2007. Impact of subsoil water use on wheat yield. Austr. J. Agricult. Res. 58:303-315.

López-Castaneda, C., Richards, R.A., Farquhar, G.D., Williamson, R.E. 1996. Seed and seedling characteristics contributing to variation in early vigor among temperate cereals. Crop Sci. 36:1257-1266.

Lynch, J.P. 2007. Roots of the second Green Revolution. Aust. J. Bot. 55:493-512.

Parry, M.A.J., Reynolds, M., Salvucci, M.E., Raines, C., Andralojc, P.J., Zhu, X.G., Price, G.D., Condon, A.G., Furbank, R.T. 2011. Raising yield potential of wheat II. Increasing photosynthetic capacity and efficiency. J. Exp. Bot. 62:453-467.

Rajaram, S., van Ginkel, M. 1996. Yield potential debate: germplasm vs. methodology, or both. In: Reynolds, M.P., Rajaram, S., McNab, A. (eds), Increasing Yield Potential in Wheat: Breaking the Barriers. Workshop Proc. CD. Obregon, Mexico, 28-30 Mar. 1996. CIMMYT. Mexico DF, Mexico.

Reynolds, M., Bonnett, D., Chapman, S.C., Furbank, R.T., Manes, Y., Mather, D.E., Parry, M.A.J. 2011. Raising yield potential of wheat. I. Overview of a consortium approach and breeding strategies. J. Exp. Bot. 62:439-452.

Reynolds, M.P., Delgado, M.I., Gutiérrez-Rodríguez, M., Larqué-Saavedra, A. 2000. Photosynthesis of wheat in a warm, irrigated environment I: Genetic diversity and crop productivity. Field Crops Res. 66:37-50.

Richards, R.A. 2000. Selectable traits to increase crop photosynthesis and yield of grain crops. J. Exp. Bot. 51:447-458.

Richards, R.A., Rebetzke, G.J., Watt, M., Condon, A.G., Spielmeyer, W., Dolferus, R. 2010. Breeding for improved water productivity in temperate cereals: phenotyping, quantitative trait loci, markers and the selection environment. Functional Plant Biol. 37:85-97.

Sadras, V.O., Lawson, C. 2011. Genetic gain in yield and associated changes in phenotype, trait plasticity and competitive ability of South Australian wheat varieties released between 1958 and 2007. Crop and Pasture Sci. 62:533-549.

Sanchez-Garcia, M., Royo, C., Aparicio, N., Martin-Sanchez, J.A., Alvaro, F. 2013. Genetic improvement of bread wheat yield and associated traits in Spain during the $20^{\text {th }}$ century. J. Agricult. Sci. 151:105-118.

Tian, Z., Jing, Q., Dai, T., Jiang, D., Cao, W. 2011. Effects of genetic improvements on grain yield and agronomic traits of winter wheat in the Yangtze River Basin of China. Field Crops Res. 124:417-425.

Thorne, G.N. 1974. Physiology of grain yield of wheat and barley. In: Rothamsted Experimental Station, Report for 1973, Part 2. Rothamsted Experimental Station, Hertfordshire, UK. pp. 5-25. 
Zheng, T.C., Zhang, X.K., Yina, G.H., Wanga, L.N., Hana, Y.L., Chen, L., Huanga, F., Tanga, J.W., Xiad, X.C., Hed, Z.H. 2011. Genetic gains in grain yield, net photosynthesis and stomatal conductance achieved in Henan Province of China between 1981 and 2008. Field Crops Res. 122:225-233.

\section{Electronic Supplementary Material (ESM)}

Electronic Supplementary Material (ESM) associated with this article can be found at the website of CRC at http://www.akademiai.com/content/120427/

Electronic Supplementary Table S1. List of genotypes included in experiment

Electronic Supplementary Table S2. Weather data of wheat growing season for 2012-2013 and 2013-2014

Electronic Supplementary Figure S1. Regression analysis for chlorophyll 'a'

Electronic Supplementary Figure S2. Regression analysis for total chlorophyll content

Electronic Supplementary Figure S3. Regression analysis for root length

Electronic Supplementary Figure S4. Regression analysis for root weight

Electronic Supplementary Figure S5. Regression analysis for NDVI 2 